\section{$\underset{\substack{\text { hommes } \\ \text { \& migrations }}}{ }$}

\section{Hommes \& migrations}

Revue française de référence sur les dynamiques

migratoires

$1315 \mid 2016$

Ondes de choc

\title{
Bruno Loth, Dolorès
}

Paris, La Boîte à bulles, 2016, 80 p., $18 €$

\section{Mustapha Harzoune}

\section{(2) OpenEdition}

\section{Journals}

Édition électronique

URL : http://journals.openedition.org/hommesmigrations/3762

DOI : 10.4000/hommesmigrations.3762

ISSN : 2262-3353

\section{Éditeur}

Musée national de l'histoire de l'immigration

\section{Édition imprimée}

Date de publication : 1 juillet 2016

Pagination : 152-153

ISBN : 978-2-919040-36-0

ISSN : $1142-852 X$

\section{Référence électronique}

Mustapha Harzoune, «Bruno Loth, Dolorès », Hommes \& migrations [En ligne], 1315 | 2016, mis en ligne le 01 juillet 2016, consulté le 24 septembre 2020. URL : http://journals.openedition.org/

hommesmigrations/3762; DOI : https://doi.org/10.4000/hommesmigrations.3762 
gober des mensonges. Éloi Laurent déploie son propos en trois thèmes le néolibéralisme, l'écolo-scepticisme et la social xénophobie pour dire le fait que les extrêmes droites substituent désor mais au "trop d'immigrés "d'hier un "trop-d'immigrés pour trop peu de res sources disponibles

Eing "mythes "sont alors déboulonnés: te "grand remplacement ", le "coûtéco Aonique insupportable "et les charges sociales "insoutenables "de l'immi gration, le mythe du "pauvre Blanc, du périurbain oublié "et l'impossible assimilation desimmigrés.

t'auteur ne refuse pas la discussion ehiffrée, au contraire. À chaque fois et ì chaque entrée, statistiques, rap ports, études économiques ou démo graphiques ì l'appui, it montre que ees " mythes "sont des mystifiez tions: le "grand remplacement "est une absurdité démographique. Ce qui

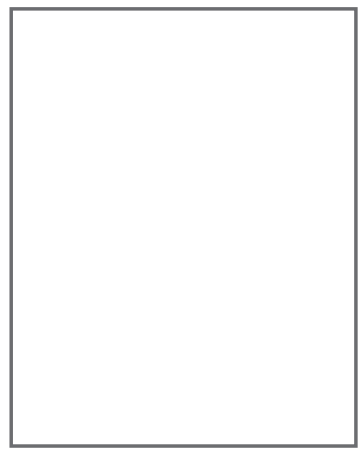

\section{Bruno Loth}

\section{Dolorès}

Paris, La Boîte à bulles, 2016, 80 p., $18 €$

Février 2015. L'histoire s'ouvre dans une maison de retraite bordelaise. Alignées en rang d'oignon devant un poste de télévision, quatre fringantes vénérables devisent et se chambrent, un peu. "Moi, un bateau va venir me chercher " répète Marie. "C'est pas un bateau qui va venir te chercher, c'est l'ambulance "lui eoûte ce ne sont pas les immigrés contributeurs nets aux budgets sociau* -maisle grandapparvisement "qui se double d'inégalités territoriales que te mythe du périurbain oublié-occulte en négligeant "de comprendre l'am pleur des inégalités dont sont victimes tes territoires défavorisés, en ne vou lant voir que la couleur de la peau de teurs habitants ". Et sur l'impossible assimilation des personnes immigrées et deleurs rejetons,cen'est past'origine qui pose problème mais les "chances" effertes aux unset aux autres de pou voir s'émanciper de leur origine pour devenir socialement françaises ":.

Reste l'essentiel. Après Abdelmalek Sayad, Éloi taurent refuse de réduire te débat sur l'immigration ì un exer eice comptable et faire le jeu des xénophobes - trier entre-les "bons "et les " mauvais "immigrés. "I serait abject Austapha Harzoune

répond une autre. La vie s'expose, dérisoire et tragique, les corps abîmés, fatigués et les mémoires devenues inutiles. Marie inquiète ses filles et le personnel de l'établissement. On ne la reconnaît plus. Son état de santé semble se dégrader. Depuis peu, elle se fait appeler Dolorès et se met à parler en espagnol, elle qui jamais n'a pratiqué cette langue. Étonnant. Comme est étonnant le fait que ses deux filles ignorent tout de son enfance, plus exactement de la vie avant l'orphelinat, quand, à l'âge de sept ans, elle fut adoptée. Alors, par amour pour cette femme qui leur a donné la vie et les a élevées seule, 
Nathalie doute, s'interroge, prend au sérieux ce que d'aucuns considéreraient comme les délires d'une dame déjà sénile, ou pas loin.

Bruno Loth revisite ici le thème du silence et de la transmission. Par des allers-retours entre le présent et le passé, le lecteur comprend vite que Marie se prénomme bien Dolorès et qu'avec ses parents républicains elle a fui, en 1939, les troupes franquistes, tentant d'embarquer sur le Stanbrook, le dernier bateau à pouvoir quitter le port d'Alicante. Bloquées sur la plage, quelques 15000 personnes - hommes, femmes et enfants - tombent dans les griffes des fascistes espagnols et italiens. Comme Doan Bui qui, dans Le Silence de mon père (L'Iconoclaste, 2016), évoque les silences d'une génération de réfugiés vietnamiens, ici Bruno Loth aborde à travers les nondits d'une autre réfugiée, cette enfant de républicains, orpheline et recueillie par une institution religieuse française, les silences (et la mémoire) des républicains espagnols dont certains " refusèrent de parler leur langue tant que Franco était en vie ».

Pour mettre des mots et des images sur ces silences, pour reconstituer cette partie d'elle-même, pour se rapprocher de sa mère, Nathalie se rend en Espagne. Elle assiste à la montée de Podemos et à l'élection à la mairie de Madrid de Manuela Carmena, du mouvement «Ahora Madrid ». L'originalité de l'ouvrage est de mêler, par un jeu de miroir, les valeurs et les idéaux des républicains aux revendications de justice, aux combats contre la corruption des militants de Podemos. "L'histoire, comme la mémoire humaine, n'est jamais absolue écrit en postface l'auteur. Nos histoires de familles ressemblent à celles de tout un peuple, elles influencent constamment notre avenir et la manière dont nous nous approprions le passé."

L'autre actualité, qui entre en résonance avec cette mémoire espagnole oubliée, est celle des réfugiés, syriens notamment. Il fut un temps où, en l'espace de quelques jours, du 28 janvier au 15 février 1939, la France dû accueillir pas moins de 500 ooo réfugiés espagnols. Mal, souvent... mais au moins, les portes ne furent pas fermées.

Dolorès n'est qu'un prétexte pour l'auteur - on peut le regretter pour la consistance des personnages - pour revenir sur la mémoire de la Guerre civile espagnole et l'exil des républicains. Le texte, didactique et documenté, n'a pas l'énergie ou la force des dessins, en noir et blanc et en sépia. Des dessins réalistes et précis. Sensibles aussi, à commencer par les portraits. M. H. 